Оригинальная статья/Original article

УДК 641.05

DOI: http://doi.org/10.20914/2310-1202-2018-2-211-219

\begin{tabular}{c} 
Особенности разработки рационов питания для детей дошкольного \\
возраста больных целиакией \\
\hline \hline
\end{tabular}

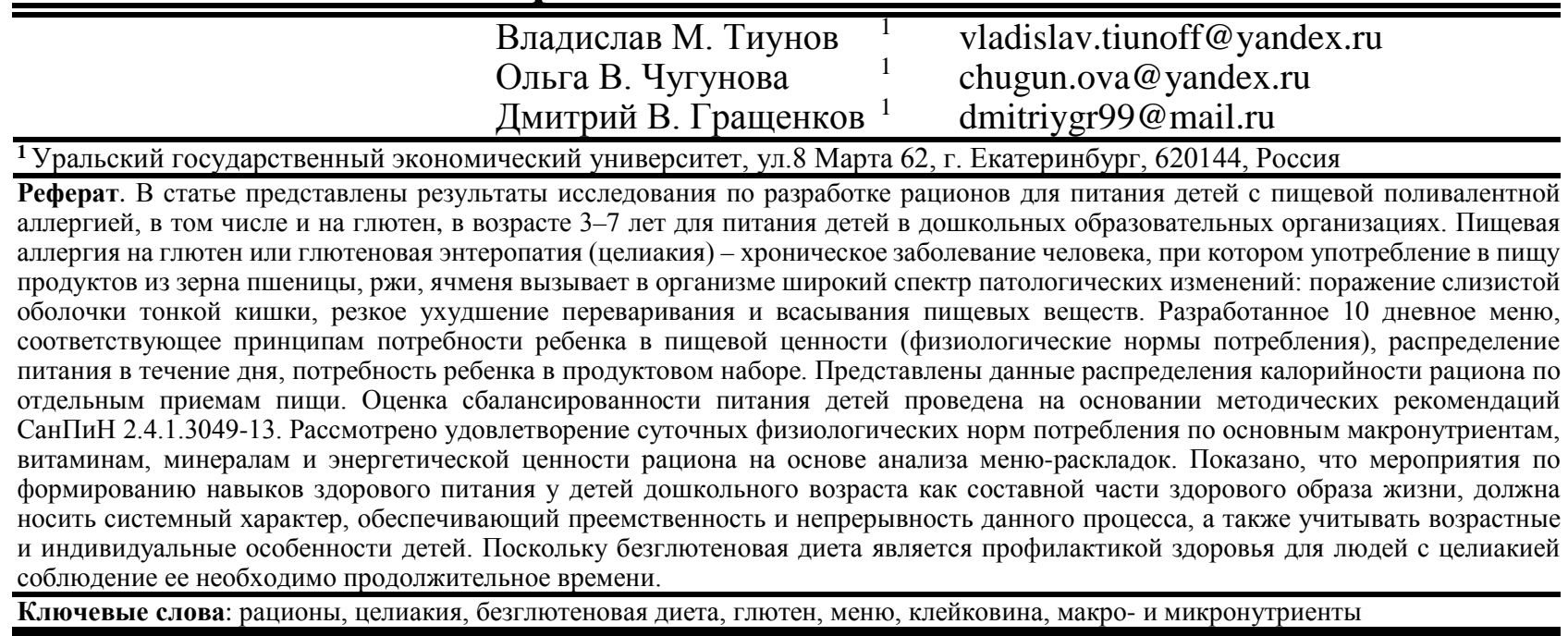

\title{
Features of the development of diets for preschool children in celiac
} patients

\begin{tabular}{l}
\hline $\begin{array}{r}\text { Vladislav M. Tiunov } \\
\text { Olga V. Chugunova }\end{array} \begin{array}{l}1 \\
\text { Dmitrii V. Grashchenkov } 1\end{array}$ \\
$\begin{array}{l}\text { vladislav.tiunoff@yandex.ru } \\
\text { chugun.ova@yandex.ru } \\
\text { dmitriygr99@mail.ru }\end{array}$ \\
$\begin{array}{l}\text { 1 Ural State Univercity of Economics, 8 Marta str., 62, Ekaterinburg, 620144, Russia } \\
\text { Summary.The article presents the results of a study on the development of diets for feeding children with food polyvalent allergy, incl. and } \\
\text { gluten at the age of 3-7 years for feeding children in pre-school educational organizations. Food allergies to gluten or gluten enteropathy } \\
\text { (celiac disease) is a chronic human disease in which eating food from wheat, rye, and barley grain causes a wide range of pathological changes } \\
\text { in the body: damage to the small intestine mucosa, a sharp deterioration in the digestion and absorption of nutrients. The developed 10 day } \\
\text { menu, corresponding to the principles of the child's nutritional needs (physiological norms of consumption), distribution of nutrition during } \\
\text { the day, the child's need for food. The data of caloric distribution of the diet for individual meals are presented. The evaluation of the nutrition } \\
\text { balance of children was carried out on the basis of the SanPiN guidelines 2.4.1.3049-13. Satisfaction of diurnal physiological norms of } \\
\text { consumption on the main macronutrients, vitamins, minerals and energy value of the diet on the basis of the analysis of menu-layouts is } \\
\text { considered. It is shown that measures to form healthy food habits in preschool children as part of a healthy lifestyle should be systemic, } \\
\text { ensuring continuity and continuity of this process, as well as taking into account the age and individual characteristics of children. Since the } \\
\text { gluten-free diet is a health preventive for people with celiac compliance, it needs a long time. }\end{array}$ \\
\hline Keywords:rations, celiac disease, gluten-free diet, gluten, menus, gluten, macro and micronutrients \\
\hline \hline
\end{tabular}

\section{Введение}

Одним из основных направлений государственной политики в сфере обеспечения продовольственной безопасности Российской Федерации является осуществление мер повышения экономической доступности пищевых продуктов для всех групп населения, направленных на организацию здорового питания детей раннего, дошкольного и школьного возраста. Сбалансированное и рациональное питания в детском возрасте способствует профилактике развития многих алиментарно-зависимых заболеваний, также, оно способствует повышению условию физического и интеллектуального развития организма детей.

\section{Для цитирования}

Тиунов В.М., Чугунова О.В., Грашченков Д.В. Особенности разработки рационов питания для детей дошкольного возраста больных целиакией // Вестник ВГУИТ. 2018. Т. 80. № 2. С. 211-219. doi:10.20914/2310-1202-2018-2-211-219
Питание напрямую оказывает существенное влияние на формирование и состояние здоровья человека на протяжении всей последующей жизни.

Однако, несмотря на важную роль питания в жизни человека, в современное время эта проблема в России перешла из ряда медицинских в общегосударственную [1].

Как отмечено в «Основах государственной политики РФ в области здорового питания населения на период до 2020 г.», «питание большинства населения не соответствует принципам здорового питания из-за потребления пищевых продуктов, содержащих большое количество жира животного происхождения и простых

For citation

Tiunov V.M., Chugunova O.V., Grashchenkov D.V. Features of the development of diets for preschool children in celiac patients. Vestnik VGUIT [Proceedings of VSUET]. 2018. vol. 80. no. 2. pp. 211-219. (in Russian). doi:10.20914/2310-1202-2018-2-211-219 
углеводов, недостатка в рационе овощей и фруктов, рыбы и морепродуктов, что приводит к увеличивая риск развития сахарного диабета, заболевания сердечно-сосудистой системы и других заболеваний» [2].

Одним из приоритетных направлений реализации государственной политики является развитие производства пищевых продуктов, а также, развитие направления специализированных продуктов питания, как для взрослого населения, так и для детей разных возрастов.

Пищевая аллергия на глютен или глютеновая энтеропатия (целиакия) - хроническое заболевание человека, при котором употребление в пищу продуктов из зерна пшеницы, ржи, ячменя вызывает в организме широкий спектр патологических изменений: поражение слизистой оболочки тонкой кишки, резкое ухудшение переваривания и всасывания пищевых веществ [3].

Установлено [3, 8, 9], что медикаментов для лечения целиакии не существует. Единственный путь для больных целиакией - пожизненно соблюдать безглютеновую диету, для соблюдения которой должны быть полностью исключены продукты, содержащие в своем составе глютен. Это белок, содержащийся в хлебных злаках, к примеру, в пшенице, ржи, ячмене и так далее. В его состав входит вещество L-глиадин, которое оказывает токсичное воздействие на слизистую и ведет к нарушению процесса абсорбции питательных компонентов в кишечнике.

Целиакия является генетически обусловленным нарушением функции тонкого кишечника, которое связано с дефицитом ферментов, расщепляющих глютен. На фоне патологии развивается мальабсорбция, имеющая различную степень выраженности и сопровождающаяся пенистой диареей, а также такими симптомами, как метеоризм, похудение, сухость кожи и задержка физического развития детей.

Безглютеновая диета является основополагающим аспектом в лечении этой болезни. Полное исключение глютена из рациона ребенка гарантированно устранит его разрушающее действие на стенки молодого кишечника. В результате симптоматика заболевания полностью исчезнет. Диета при целиакии у детей подразумевает запрет следующих видов продуктов:

- любые продукты, a также блюда с добавлением овса, ржи, ячменя или пшеницы;

- макаронные или хлебобулочные продукты наряду с печеньем, тортами, пирожными и так далее;

- мороженое и йогурты;

- блюда на основе мясных полуфабрикатов или колбас;
- различные соусы и консервы;

- цельное молоко также считается нежелательным для ребенка.

Исключение из рациона различных пищевых продуктов легко приводит к пищевому дисбалансу и провоцирует формирования дефицита минеральных солей, витаминов, белков, жиров. Например, при удалении злаков закономерно возникает дефицит селена, витаминов Е, группы В, белка, растительной клетчатки. При исключении молочной группы продуктов кальция, витаминов А и Д, лактозы.

Исходя из этого, разработка рациона для детей с целиакией для питания в дошкольных образовательных учреждениях (ДОУ) является актуальной.

Правильно организованное, построенное на современных научных основах рациональное сбалансированное питание является одним из наиболее важных биологических и социальных факторов, поскольку, наряду с удовлетворением потребности в пищевых веществах, оно должно обеспечивать процессы роста и развития организма в детском возрасте [5].

Санитарно-эпидемиологические требования к организации питания в дошкольных образовательных организациях регламентированы СанПиН 2.4.1.3049-13.

При организации питания выделяются следующие основные требования:

- потребность ребенка в пищевой ценности (физиологические нормы потребления);

- распределение питания в течение дня; наборе;

- потребность ребенка в продуктовом

- способ приготовления и вкусовые качества пищи.

\section{Результаты и обсуждение}

Рациональное питание строится на основе физиологических потребностей организма ребенка в различных пищевых веществах и энергии. Разработка физиологических норм питания, составление пищевых рационов для организации питания детей, введение в рацион новых продуктов основаны на учении о сбалансированном питании. Сбалансированное питание отражает потребность в пищевых веществах и взаимосвязи между ними [5].

Необходимое количество питательных веществ и энергетическая ценность (ккал) одинаковы для детей с целиакией и для здоровых детей тех же возрастных групп. На сайте Министерства здравоохранения указаны рекомендуемые нормы энергетических и питательных веществ. У детей, в питание которых долгое время не был включен глютен, не должны развиваться проблемы, связанные с недостатком каких-либо витаминов и минеральных веществ. 
Как правило, питание детей дошкольного возраста осуществляется преимущественно в организованных коллективах (ДОУ) и семье. И если в семье родители могут контролировать рацион ребенка с пищевой аллергией на глютен, то в детском дошкольном учреждении на данный момент времени существуют определённые проблемы с внедрением в систему безглютенового рациона для детей.

При разработке безглютенового рациона следует соблюдать те же требования что и для стандартного рациона. Однако при составлении рациона для больных целиакией необходимо исключить ряд пищевых продуктов, блюд и кулинарных изделий, содержащих глютен.

При формировании безглютенового рациона для детей с пищевой аллергией на глютен должны соблюдаться определенные правила и принципы оптимального питания (рисунок 1). Для организации оптимального питания в ДОУ необходимо иметь правильно составленное меню не менее чем на 2 недели, с разнообразным набором блюд и кулинарных изделий, не содержащих глютен. Рацион должен удовлетворять потребности во всех основных ингредиентах питания и энергии.

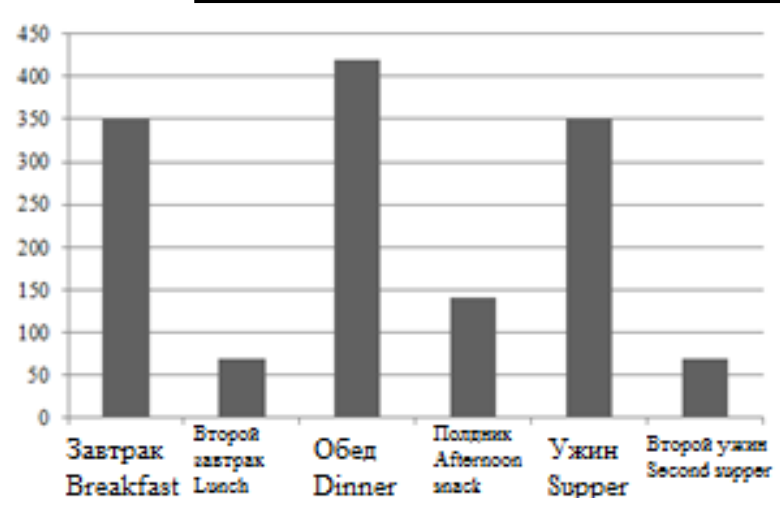

Рисунок 1. Схема общих принципов формирования рационов питания в ДОУ.

Figure 1. Scheme of general principles for the formation of diets in the preschool.

Рекомендации рационального питания подразумевают оптимальное соотношение макронутриентов, то есть количество белков, жиров и углеводов, которое по массе должно составлять 1:1:4. Вклад белка в общую калорийность должен быть 12-15\%, жира: 30-32\%, углеводов - от 55 до 58\%. Среднее рекомендуемое распределение калорийности по отдельным приемам пищи для детей разных возрастов указанно на рисунке 2.

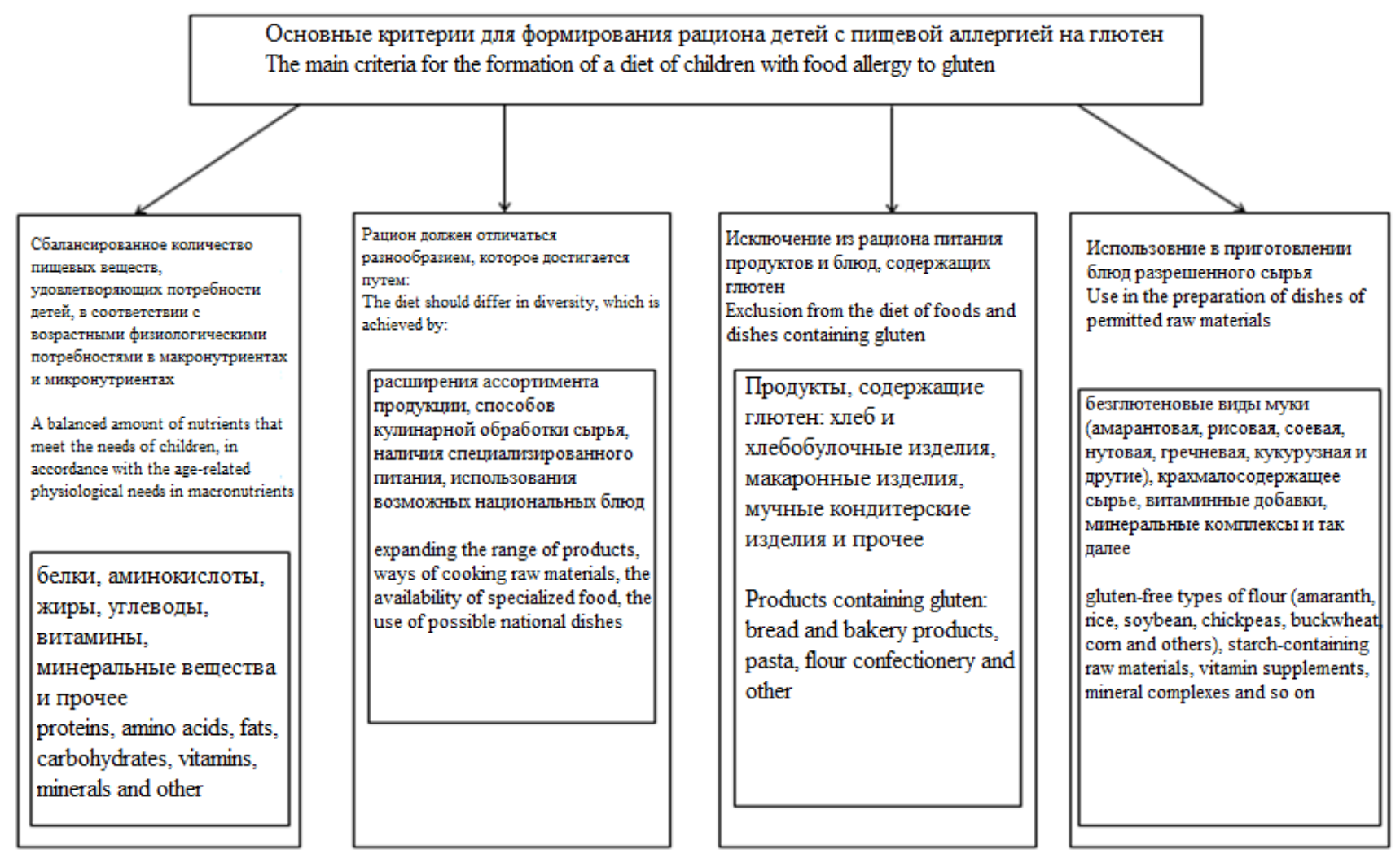

Рисунок 2. Среднее рекомендуемое распределение калорийности по отдельным приемам пищи для детей 3-7 лет, ккал Figure 2. Average recommended caloric distribution for individual meals for children 3-7 years, kcal 
Кроме того, исходя из представленных данных на рисунке 2, необходимо допустить отступление от средней нормы калорийности по отдельным приемам пищи в течение дня в пределах $\pm 10 \%$.

Фактическое питание детей, посещающих дошкольные образовательные организации, изучали расчетным методом (с составлением технической документации - технологические карты) по меню-раскладкам (ОКУД 0504202) суточных рационов [6].

Исходя из меню рационов действующих дошкольных организаций Свердловской области (составлена выборка рационов питания по данным наиболее крупного оператора по питанию в Свердловской области), а также учитывая, потребности в рационе для детей наличия сбалансированного количества микро и макро нутриентов, минеральных веществ, витаминов, а также отсутствия в рационе продуктов и блюд, содержащих глютен, авторами составлен и проанализирован двухнедельный рацион питания (десять дней) для детей с пищевой аллергии на глютен. В структуру рациона включен завтрак, второй завтрак, обед, уплотненный полдник. Меню рациона проанализировано по пищевой ценности (содержание белков, жиров, углеводов, калорийности и витаминноминеральному составу), расходу продуктов (массой брутто и нетто за каждый день и 2 недели).

С использованием компьютерной программы «Системе расчетов для общественного питания» [7] рассчитывали пищевую и энергетическую ценность отдельных рецептур и меню рационов.

Расчет осуществлялся с использованием справочных данных о химическом составе продуктов и других источников. При расчете пищевой и энергетической ценности рационов учитывали потери нутриентов в процессе кулинарной обработки (механической и тепловой) [3].

Анализ двухнедельного рациона детей с пищевой аллергией на глютен по основным макронутриентам и пищевой ценности представлен в таблице 1.
Оценка сбалансированности питания детей проведена на основании методических рекомендаций СанПиН 2.4.1.3049-13. Из представленных данных в таблице 1 видно, что в большей степени калорийность рациона за день не превышает нормы, однако, наблюдается избыток таких макронутриентов, как белки (в среднем на 17\%) и пищевых волокон в среднем на 20\%). Следует обратить внимание, что превышение содержания белка зафиксировано в фактическом рационе дошкольной организации, за счет питания ребенка дома превышение будет еще больше.

Также, не стоит забывать о факторе того, что необходимо допустить отступление от средней нормы калорийности за день в рационе в пределах $\pm 10 \%$. Кроме этого, в представленном рационе отмечается общая несбалансированность пищевой ценности по дням(как недостаток, так и превышение). Исходя из этого, можно сказать, что представленный результат в большей степень является допустимой поправкой.

Пищевые волокна являются балластными веществами и используются для профилактики и лечения атеросклероза, ишемической болезни сердца, онкопатологии, сахарного диабета, болезни органов пищеварительной системы [4]. Тем не менее, в представленном рационе, избыток пищевых волокон на - 20\% не является недостатком потому, что рекомендуемой суточной дозой пищевых волокон считается 25-40 г. Однако, исследования показывают, что у людей, страдающих от пищевой аллергии на глютен не хватает пищевых волокон, возникающих в следствии пожизненной безглютеновой диеты, что приводит к запорам, геморрою, опухоли кишечника и недостаточности желчевыводящих путей. Исходя из этого коррекция рациона с незначительным избытком пищевых волокон у таких людей совершенно необходима.

Степень суточного удовлетворения в пищевых веществах и калорийности рациона

Таблица 1. Table 1.

The degree of daily satisfaction in nutrients and caloric intake

\begin{tabular}{|c|c|c|c|c|c|c|}
\hline $\begin{array}{c}\text { День } \\
\text { Day }\end{array}$ & $\begin{array}{c}\text { Показатель } \\
\text { Indicator }\end{array}$ & $\begin{array}{c}\text { Белки, г } \\
\text { Protein, g }\end{array}$ & $\begin{array}{c}\text { Жиры, г } \\
\text { Fat, g }\end{array}$ & $\begin{array}{c}\text { Углеводы, г } \\
\text { Carbohydrates, g }\end{array}$ & $\begin{array}{c}\text { Пищевые во- } \\
\text { локна, г } \\
\text { Dietary fiber, g }\end{array}$ & $\begin{array}{c}\text { Энергетическая цен- } \\
\text { ность,ккал } \\
\text { Energy value, kcal }\end{array}$ \\
\hline 1 & 2 & 3 & 4 & 5 & 6 & 7 \\
\cline { 2 - 7 } & $\begin{array}{c}\text { Нормативное значение } \\
\text { Normative value }\end{array}$ & 42 & 47 & 203 & 8 & 1400 \\
\hline \multirow{2}{*}{1} & 3начение |Value & 54,2 & 49,8 & 193,4 & 17,5 & 1319 \\
\cline { 2 - 7 } & $\begin{array}{c}\text { \% от суточного удовле- } \\
\text { творения | }\end{array}$ & 129,0 & 105,9 & 95,5 & 218,7 & 94,2 \\
\hline
\end{tabular}


Продолжение табл. 1 / Continuation of Table 1

\begin{tabular}{|c|c|c|c|c|c|c|}
\hline 1 & 2 & 3 & 4 & 5 & 6 & 7 \\
\hline \multirow[b]{2}{*}{2} & Значение | Value & 47,0 & 46,2 & 162,8 & 13,3 & 1280 \\
\hline & $\begin{array}{c}\text { \% от суточного } \\
\text { удовлетворения | } \\
\% \text { of daily satisfaction }\end{array}$ & 111,9 & 98,2 & 80,1 & 166,2 & 91,4 \\
\hline \multirow[b]{2}{*}{3} & Значение | Value & 39,2 & 38,0 & 222,6 & 14,1 & 1410 \\
\hline & $\begin{array}{c}\text { \% от суточного } \\
\text { удовлетворения | } \\
\% \text { of daily satisfaction }\end{array}$ & 93,3 & 80,8 & 109,6 & 176,2 & 100,7 \\
\hline \multirow[b]{2}{*}{4} & Значение | Value & 51,7 & 39,7 & 139,1 & 14,3 & 1150 \\
\hline & $\begin{array}{c}\text { \% от суточного } \\
\text { удовлетворения | } \\
\% \text { of daily satisfaction }\end{array}$ & 123,1 & 84,4 & 68,5 & 178, & 82,4 \\
\hline \multirow[b]{2}{*}{5} & Значение |Value & 56,7 & 53,2 & 195,6 & 17,3 & 1482 \\
\hline & $\begin{array}{c}\text { \% от суточного } \\
\text { удовлетворения | } \\
\% \text { of daily satisfaction }\end{array}$ & 135 & 113,1 & 91,4 & 216,3 & 105,8 \\
\hline \multirow[b]{2}{*}{6} & Значение | Value & 46,7 & 42,1 & 12,3 & 6,9 & 1055 \\
\hline & $\begin{array}{c}\text { \% от суточного } \\
\text { удовлетворения | } \\
\% \text { of daily satisfaction }\end{array}$ & 102,11 & 89,5 & 55,3 & 86,2 & 75,3 \\
\hline \multirow[b]{2}{*}{7} & Значение | Value & 54,7 & 48,1 & 159,0 & 12,3 & 1266 \\
\hline & $\begin{array}{c}\text { \% от суточного } \\
\text { удовлетворения | } \\
\% \text { of daily satisfaction }\end{array}$ & 130,2 & 102,3 & 78,3 & 153,7 & 90,5 \\
\hline \multirow[b]{2}{*}{8} & Значение | Value & 46,3 & 24,1 & 152,7 & 6,5 & 1030 \\
\hline & $\begin{array}{c}\text { \% от суточного } \\
\text { удовлетворения | } \\
\% \text { of daily satisfaction }\end{array}$ & 110,2 & 51,2 & 75,3 & 81,2 & 76,4 \\
\hline \multirow[b]{2}{*}{9} & Значение | Value & 36,4 & 42,9 & 128,8 & 8,1 & 1108 \\
\hline & $\begin{array}{c}\text { \% от суточного } \\
\text { удовлетворения | } \\
\% \text { of daily satisfaction }\end{array}$ & 86,6 & 91,2 & 63,4 & 101,2 & 80,1 \\
\hline \multirow[b]{2}{*}{10} & Значение / Value & 49,9 & 48,8 & 149,5 & 10,9 & 1217 \\
\hline & $\begin{array}{c}\text { \% от суточного } \\
\text { удовлетворения | } \\
\% \text { of daily satisfaction }\end{array}$ & 118,2 & 103,3 & 73,6 & 136,2 & 87,1 \\
\hline \multirow{2}{*}{\multicolumn{2}{|c|}{$\begin{array}{l}\text { Средние значения } \\
\text { Mean values } \\
\end{array}$}} & 49,2 & 43,3 & 154,9 & 12,2 & 1227 \\
\hline & & 117,3 & 92,2 & 996,1 & 120,2 & 89,9 \\
\hline
\end{tabular}

Что касается таких макронутриентов как, жиры и углеводы то в представленном нами рационе они соответствуют норме, среднее значение жиров от суточного удовлетворения $92,2 \%$, и углеводов соответственно - 96,1\%.

Показатель энергетической ценности в представленном рационе от суточного удовлетворения составляет - 89,9\%. На рисунке 3 отображен энергетический баланс представленного 10-дневного рациона в процентном соотношении для детей 3-7 лет.

В таблице 2 представлена степень суточного удовлетворения в содержание витаминов в рационе.

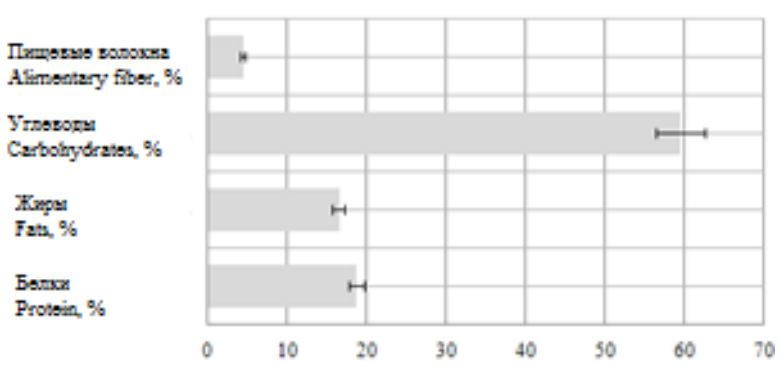

Рисунок 3. Энергетический баланс представленного 10 -дневного рациона в процентном соотношении для детей 3-7 лет

Figure 3. The energy balance of the presented 10-day diet as a percentage for children aged 3-7 
Таблица 2.

Степень суточного удовлетворения в содержание витаминов рациона

Table 2.

The degree of daily satisfaction in the content of vitamin ration

\begin{tabular}{|c|c|c|c|c|c|}
\hline \multirow[b]{2}{*}{$\begin{array}{l}\text { День } \\
\text { Day }\end{array}$} & $\begin{array}{l}\text { Показатель | Indicator } \\
\end{array}$ & \multirow{2}{*}{$\begin{array}{c}\mathrm{B}_{1}, \mathrm{M \Gamma} \\
0,8\end{array}$} & \multirow{2}{*}{$\begin{array}{c}\mathrm{B}_{2}, \mathrm{M \Gamma} \\
0,9\end{array}$} & \multirow{2}{*}{$\begin{array}{c}\text { E, мкг } \\
5\end{array}$} & \multirow{2}{*}{$\begin{array}{c}\mathrm{C}, \mathrm{MI} \\
50\end{array}$} \\
\hline & $\begin{array}{l}\text { Нормативное значение | } \\
\text { Normative value }\end{array}$ & & & & \\
\hline \multirow[b]{2}{*}{1} & \begin{tabular}{l|l|} 
Значение & Value \\
\end{tabular} & 0,9 & 1,4 & 9,9 & 215 \\
\hline & $\begin{array}{l}\text { \% от суточного удовлетворения } \\
\% \text { of daily satisfaction }\end{array}$ & 112,5 & 155,5 & 198 & 150 \\
\hline \multirow[b]{2}{*}{2} & Значение | Value & 0,7 & 1,1 & 10,8 & 93,3 \\
\hline & $\begin{array}{l}\text { \% от суточного удовлетворения } \\
\text { \% of daily satisfaction }\end{array}$ & 87,5 & 122,2 & 216 & 126 \\
\hline \multirow[b]{2}{*}{3} & Значение | Value & 5,3 & 2,3 & 10,6 & 103,7 \\
\hline & $\begin{array}{l}\text { \% от суточного удовлетворения } \\
\% \text { of daily satisfaction }\end{array}$ & 666,2 & 255,5 & 212 & 107,4 \\
\hline \multirow[b]{2}{*}{4} & \begin{tabular}{l|l|l} 
Значение & Value \\
\end{tabular} & 0,7 & 1,4 & 10,0 & 185,3 \\
\hline & $\begin{array}{l}\text { \% от суточного удовлетворения } \\
\% \text { of daily satisfaction }\end{array}$ & 87,5 & 155,5 & 200 & 170,6 \\
\hline \multirow[b]{2}{*}{5} & Значение | Value & 2,2 & 1,7 & 11,3 & 196,2 \\
\hline & $\begin{array}{l}\text { \% от суточного удовлетворения } \\
\% \text { of daily satisfaction }\end{array}$ & 275 & 188,8 & 226 & 192,4 \\
\hline \multirow[b]{2}{*}{6} & Значение | Value & 0,5 & 1,1 & 9,5 & 58,7 \\
\hline & $\begin{array}{l}\text { \% от суточного удовлетворения } \\
\% \text { of daily satisfaction }\end{array}$ & 62,5 & 122,2 & 190 & 117,4 \\
\hline \multirow[b]{2}{*}{7} & \begin{tabular}{l|l|l} 
Значение & Value \\
\end{tabular} & 2,1 & 1,5 & 7,2 & 94,9 \\
\hline & $\begin{array}{l}\text { \% от суточного удовлетворения } \\
\% \text { of daily satisfaction }\end{array}$ & 262,5 & 166,6 & 144 & 189,8 \\
\hline \multirow[b]{2}{*}{8} & Значение | Value & 0,7 & 1,0 & 8,9 & 189,0 \\
\hline & $\begin{array}{l}\text { \% от суточного удовлетворения } \\
\% \text { of daily satisfaction }\end{array}$ & 87,5 & 111,1 & 178 & 178 \\
\hline \multirow[b]{2}{*}{9} & Значение | Value & 2,2 & 2,1 & 8,2 & 82,5 \\
\hline & $\begin{array}{l}\text { \% от суточного удовлетворения } \\
\% \text { of daily satisfaction }\end{array}$ & 275 & 233,3 & 164 & 165 \\
\hline \multirow[b]{2}{*}{10} & Значение | Value & 0,7 & 1,2 & 11,7 & 95,4 \\
\hline & $\begin{array}{l}\text { \% от суточного удовлетворения } \\
\% \text { of daily satisfaction }\end{array}$ & 87,5 & 133,3 & 234 & 190,8 \\
\hline \multirow{2}{*}{\multicolumn{2}{|c|}{$\begin{array}{l}\text { Средние значения } \\
\text { Mean values }\end{array}$}} & 1,6 & 1,4 & 9,8 & 79,4 \\
\hline & & 200 & 164,4 & 196 & 158 \\
\hline
\end{tabular}

На рисунке 4 отображен баланс минерального комплекса, представленного 10-дневного рациона в процентном соотношении для детей 3-7 лет.

Данные представленные в таблице 2 указывают на то что, в рационе содержание витаминов превышает нормативные значения. Однако, учитывая особенности построения рациона для детей с целиакией стоит, учесть, что, отказываясь от традиционных продуктов питания, организм также, отказывается и от витаминов, которые содержаться в них, в конечном итоге это приводит к авитаминозу.

Так, к примеру, основными продуктами, от которых стоит отказаться при целиакии, являются мучные изделия из пшеничной муки и поскольку данные группы продуктов содержат клейковину, зерновые являются хорошим источником витаминов группы В.

Необходимо отметить переизбыток витаминов группы В.Степень суточного удовлетворения в витамине $\mathrm{B}_{1}$ превышает в рационе на $-100 \%$, а содержание витамина $\mathrm{B}_{2} \mathrm{Ha}-64 \%$.
Недостаток в организме витамина $\mathrm{C}$ приводит к ослаблению иммунной системы, целому ряду нарушений и является причиной такого острого заболевания, как цинга [7] содержание его в рационе превышает на - 58\%.

На рисунке 4 отображен баланс минерального комплекса, представленного 10-дневного рациона в процентном соотношении для детей 3-7 лет.

Основными характерными проблемами для 99\% больных целиакией являются дефицит магния $(\mathrm{Mg})$ и дефицит железа $(\mathrm{Fe})$.

Данная проблема является вытекающим фактором безглютеновой диеты, основанной на не сбалансированном рационе.

В данном рационе, основываясь на правилах замены продуктов питания содержания магния от суточного удовлетворения составляет 198,8 \%, а железа - 116,8 \% (таблица 3).

Для обеспечения витаминной и минеральной сбалансированности в рацион включены продукты питания с высоким содержанием магния, железа и витаминов группы В. 


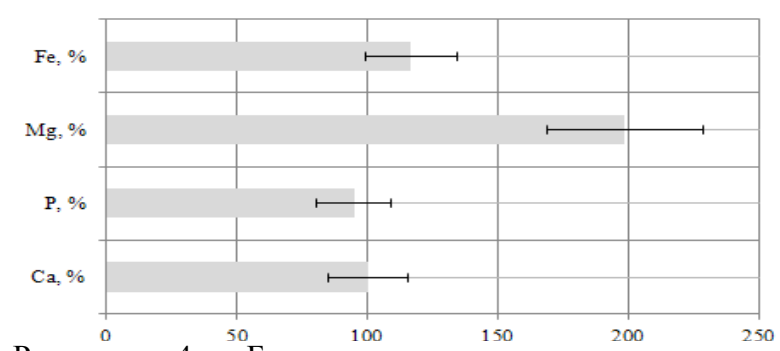

Рисунок 4. Баланс минерального комплекса представленного 10-дневного рациона в процентном соотношении для детей 3-7 лет

Figure 4. The balance of the mineral complex represented by a 10-day diet as a percentage for children 3-7 years

В таблице 3 представлена степень суточного удовлетворения в содержание минеральных элементов в рационе.

Дефицит железа и витаминов группы В проявляется аналогичными симптомами и лечится сбалансированным питанием. Из железа образуется гемоглобин, который участвует в переносе кислорода по кровеносной системе. Витамины группы В участвует в кровообразовании. Их совместный недостаток приводит к анемии.

Остальные микронутриенты, представленные в таблице, соответствуют нормам суточного удовлетворения, кальций (Сa)-100,4\%, и фосфор(Р)95,2\% соответственно.

На рисунке 5 отображен баланс витаминного комплекса, представленного 10 дневного рациона в процентном соотношении для детей 3-7 лет.

Таблица 3.

Степень суточного удовлетворения в содержание минеральных элементов в рационе

Table 3.

The degree of daily satisfaction in the content of mineral elements in the diet

\begin{tabular}{|c|c|c|c|c|c|}
\hline \multirow{2}{*}{$\begin{array}{l}\text { День } \\
\text { Day }\end{array}$} & \begin{tabular}{l|l|l} 
Показатель & Indicator \\
\end{tabular} & $\mathrm{Ca}, \mathrm{M \Gamma}$ & $\mathrm{P}, \mathrm{M \Gamma}$ & $\mathrm{Mg}, \mathrm{M \Gamma}$ & $\mathrm{Fe}, \mathrm{MI}$ \\
\hline & $\begin{array}{l}\text { Нормативное значение } \\
\text { Normative value } \\
\end{array}$ & 900 & 1100 & 200 & 10 \\
\hline \multirow{2}{*}{1} & \begin{tabular}{l|l|l} 
Значение | Value \\
\end{tabular} & 919,1 & 1177,3 & 412,0 & 10,3 \\
\hline & 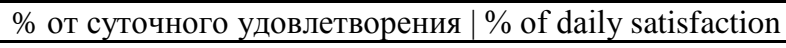 & 102,1 & 107,0 & 206 & 10 \\
\hline \multirow{2}{*}{2} & Значение | Value & 804,8 & 1014,2 & 452,2 & 15,1 \\
\hline & \begin{tabular}{l|l|l}
$\%$ от суточного удовлетворения & $\%$ of daily satisfaction
\end{tabular} & 89,4 & 92,2 & 226,1 & 151 \\
\hline \multirow{2}{*}{3} & \begin{tabular}{l|l} 
Значение & Value \\
\end{tabular} & 729,2 & 893,4 & 417,0 & 16 \\
\hline & 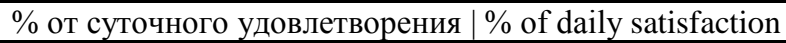 & 81,0 & 81,2 & 208,5 & 160 \\
\hline \multirow{2}{*}{4} & Значение | Value & 1038,8 & 1192,6 & 435,7 & 11,0 \\
\hline & $\begin{array}{l}\% \text { от суточного удовлетворения } \\
\end{array}$ & 115,4 & 108,4 & 217,8 & 110 \\
\hline \multirow{2}{*}{5} & Значение $\mid$ Value & 1079,2 & 1125,6 & 453,8 & 15,3 \\
\hline & $\begin{array}{l}\% \text { от суточного удовлетворения | \% of daily satisfaction } \\
\end{array}$ & 119,9 & 102,3 & 226,9 & 153 \\
\hline \multirow{2}{*}{6} & \begin{tabular}{l|l} 
Значение & Value \\
\end{tabular} & 953,2 & 1050,1 & 312,4 & 7,5 \\
\hline & $\begin{array}{l}\% \text { от суточного удовлетворения | \% of daily satisfaction } \\
\end{array}$ & 105,9 & 95,4 & 156,2 & 75 \\
\hline \multirow{2}{*}{7} & Значение | Value & 807,5 & 978,0 & 337,8 & 11,0 \\
\hline & $\begin{array}{l}\% \text { от суточного удовлетворения | } \% \text { of daily satisfaction } \\
\end{array}$ & 89,7 & 88,9 & 168,9 & 110 \\
\hline \multirow{2}{*}{8} & \begin{tabular}{l|l} 
Значение & Value \\
\end{tabular} & 823,5 & 1005,9 & 448,6 & 10,4 \\
\hline & $\begin{array}{l}\% \text { от суточного удовлетворения | } \% \text { of daily satisfaction } \\
\end{array}$ & 91,5 & 91,4 & 224,1 & 104 \\
\hline \multirow{2}{*}{9} & Значение | Value & 951,2 & 986,7 & 312,9 & 11,4 \\
\hline & \% от суточного удовлетворения |\% of daily satisfaction & 105,6 & 89,7 & 156,4 & 114 \\
\hline \multirow{2}{*}{10} & Значение | Value & 935,8 & 1056,6 & 393,6 & 13,8 \\
\hline & 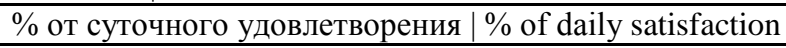 & 103,9 & 96,0 & 196,8 & 138 \\
\hline \multirow{2}{*}{\multicolumn{2}{|c|}{$\begin{array}{c}\text { Средние значения } \\
\text { Mean values }\end{array}$}} & 904,3 & 1048,1 & 358,4 & 12,7 \\
\hline & & 100,4 & 95,2 & 198,8 & 116,8 \\
\hline
\end{tabular}

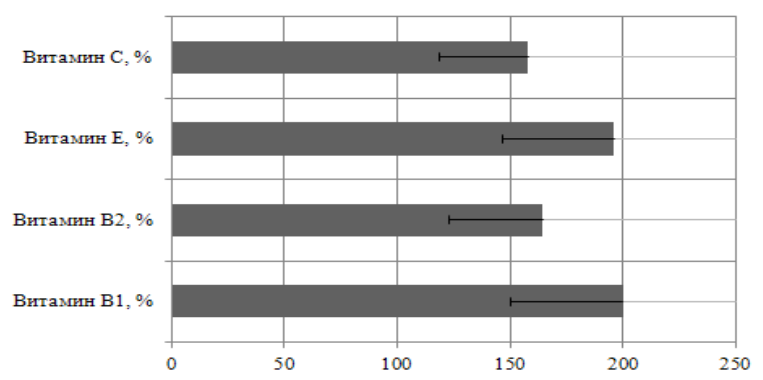

Рисунок 5. Баланс витаминного комплекса, представленного 10-дневного рациона в процентном соотношении для детей 3-7 лет

Figure 5. Balance of the vitamin complex, represented by a 10-day diet as a percentage for children 3-7 years

\section{Заключение}

Организация по формированию навыков здорового питания у детей дошкольного возраста как составной части здорового образа жизни, должна носить системный характер, обеспечивающий преемственность и непрерывность данного процесса, а также учитывать возрастные и индивидуальные особенности детей. Поскольку безглютеновая диета является профилактикой здоровья для людей с заболеванием целиакией соблюдать ее придется продолжительное количество времени, а чаще пожизненно. 
Поэтому детским дошкольным учреждениям, в которых обучаются дети с целиакией необходимо выполнять все требования для организации плавильного и сбалансированного питания. Данные требования распространяются не только на работу пищеблока, но и на состав педагогического персонала, который должен быть квалифицированным и обладать необходимой информацией. Для повышения эффективности организации питания авторами разработан рацион питания для детей с заболеванием целиакией.

Разработанный рацион в целом соответствует по содержанию и обеспечению детского организма в основных макронутриентах и суточной калорийности.

Содержание витаминов и минеральных веществ основывается на особенности построения рациона для детей с целиакией в котором,

\section{ЛИТЕРАТУРА}

1 Доктрина продовольственной безопасности Российской Федерации: Указ Президента РФ № 120 от 30.01.2010.

2 Основы государственной политики Российской Федерации в области здорового питания населения на период до 2020 года: Распоряжение Правительства РФ № 1873-р от 25 октября 2010 г.

3 Тиунов В.М., Чугунова О.В., Крюкова Е.В. Моделирование органолептических показателей качества мучных изделий из второстепенных видов муки // Технология и товароведение инновационных пищевых продуктов. 2016. № 3(38). С. 80-88.

4 Скурихина И.М., Тутельяна В.А. Химический состав российских пищевых продуктов: Справочник. М.: ДеЛипринт, 2002. 236 с.

5 Гращенков Д.В., Чугунова О.В., Кокорева Л.А. Оценка организации питания в детских дошкольных учреждениях на примере г. Екатеринбурга // Технология и товароведение инновационных пищевых продуктов. 2013. № 6. С. 95-101.

6 Гращенков Д.В., Николаева Л.И. Сборник технических нормативов для питания детей в дошкольных организациях: методические рекомендации и технические документы. Екатеринбург, 2011. 342 с.

7 Гращенков Д.В., Николаева Л.И. Система расчетов для предприятий общественного питания. Свидетельство об официальной регистрации программы для ЭВМ № 2002610284 от 26.02.2002.

8 Лазарева Т.С. Целиакия у детей и подростков // Вопросы современной педиатрии. 2008. Т. 7. № 4. C. 80-84.

9 Тутельян В.А. Химический состав и калорийность российских продуктов питания: Справочник. М.: ДеЛи плюс, 2012. 284 с.

\section{REFERENCES}

1 Doktrin prodovol'stvennoi bezopasnosti RF [The Doctrine of Food Security of the Russian Federation: Presidential Decree No. 120 of 30.01.2010] (in Russian) необходимо учесть, предрасположения детей к авитаминозу ввиду того, что он, отказываясь от традиционных продуктов питания.

Однако не стоит забывать, что существенный вклад в суточный рацион ребенка с заболеванием целиакией вносит домашнее питание. Именно под влиянием особенностей питания в семье у детей формируются вкусовые привычки, некоторые из которых могут быть преходящими, а некоторые закрепляются и становятся постоянными во взрослой жизни.

Поэтому первым фактором, служащим к выздоровлению ребенка состоит в том, чтобы оптимизировать питание детей путем предоставления полноценной безопасной пищи учитывая его особенности и физиологические нормы, а также вкусовые предпочтения.

2 Osnovy gosudarstvennoi politiki RF v oblasti zdorovogo pitaniya naseleniya [Fundamentals of the state policy of the Russian Federation in the field of healthy nutrition for the population until 2020: Order of the Government of the Russian Federation No. $1873 \mathrm{r}$ of October 25, 2010] (in Russian)

3 Tiunov V.M., Chugunova O.V., Kryukova E.V. Modeling of organoleptic indicators of quality of flour products from secondary types of flour. Tekhnologiya I tovarovedenie innovatsionnykh pishchevyjh produktov [Technology and Commodity Research of Innovative Food Products] 2016. no. 3 (38). pp. 80-88. (in Russian)

4 Skurikhina I.M., Tutelyan V.A. Khimicheskii sostav pishchevykh produktov [Chemical composition of Russian food products] Moscow, DeLiprint, 2002. 236 p. (in Russian)

5 Grashchenkov D.V., Chugunova O.V., Kokoreva L.A. An estimation of the organization of a food in children's preschool establishments on an example of Ekaterinburg. Tekhnologiya I tovarovedenie innovatsionnykh pishchevyjh produktov [Technology and товароведение innovative food products] 2013. nо. 6 . pp. 95-101. (in Russian)

6 Grashchenkov D.V., Nikolaeva L.I. Sbornik tekhnicheskikh normativov dlya pitaniya detei v doshkol'nykh organizatsiyakh [Collection of technical standards for the nutrition of children in preschool organizations: guidelines and technical documents]. Ekaterinburg, 2011. 342 p. (in Russian)

7 Grashchenkov D.V., Nikolaeva L.I. Sistema raschetov dlya predpriyatii obshchestvennogo pitaniya [Settlement system for public catering establishments. Certificate of official registration of the computer program No. 2002610284 of 26.02.2002] (in Russian)

8 Lazareva T.S. Celiac disease in children and adolescents. Voprosy sovremennoi peditrii [Questions of modern pediatrics] 2008. vol. 7. no. 4. pp. 80-84. (in Russian)

9 Tutelyan V.A. Khimicheskii sostav I kaloriinost' rossiskikh produktov pitaniya [Chemical composition and caloric content of Russian food] Moscow, DeLi Plus, 2012. 284 p. (in Russian) 


\section{СВЕДЕНИЯ ОБ АВТОРАХ}

Владислав М. Тиунов аспирант, кафедра технологии питания, Уральский государственный экономический университет, ул.8 Марта 62, г. Екатеринбург, 620144, Россия,vladislav.tiunoff@yandex.ru

Ольга В. Чугунова д.т.н., профессор, кафедра технологии питания, Уральский государственный экономический университет, ул.8 Марта 62, г. Екатеринбург, 620144, Россия,chugun.ova@yandex.ru

Дмитрий В. Гращенков к.т.н., доцент, кафедра технологии питания, Уральский государственный экономический университет, ул.8 Марта 62, г. Екатеринбург, 620144, Россия,dmitriygr99@mail.ru

\section{КРИТЕРИЙ АВТОРСТВА}

Владислав М. Тиунов обзор литературных источников по исследуемой проблеме, провёл эксперимент, выполнил расчёты

Ольга В. Чугунова консультация в ходе исследования

Дмитрий В. Гращенков написал рукопись, корректировал её до подачи в редакцию и несёт ответственность за плагиат

\section{КОНФЛИКТ ИНТЕРЕСОВ}

Авторы заявляют об отсутствии конфликта интересов.

ПОСТУПИЛА 09.03.2018

ПРИНЯТА В ПЕЧАТЬ 07.05.2018

\section{INFORMATION ABOUT AUTHORS}

Vladislav M. Tiunov graduate student, Food Technology department, Ural State Univercity of Economics, 8 Marta street, 62, Ekaterinburg, 620144, Russia,vladislav.tiunoff@yandex.ru

Olga V. Chugunova Dr. Sci. (Engin.), professor, Food Technology department, Ural State Univercity of Economics, 8 Marta street, 62, Ekaterinburg, 620144, Russia,chugun.ova@yandex.ru

Dmitrii V. Grashchenkov Cand. Sci. (Engin.), associate professor, Food Technology department, Ural State Univercity of Economics, 8 Marta street, 62, Ekaterinburg, 620144, Russia,dmitriygr99@mail.ru

\section{CONTRIBUTION}

Vladislav M. Tiunov review of the literature on an investigated problem, conducted an experiment, performed computations

Olga V. Chugunova consultation during the study

Dmitrii V. Grashchenkov wrote the manuscript, correct it before filing in editing and is responsible for plagiarism

\section{CONFLICT OF INTEREST}

The authors declare no conflict of interest.

RECEIVED 3.9.2018

ACCEPTED 5.7.2018 